\title{
Laparoscopic Adrenalectomy Formetastatic Adrenal Mass as Diagnosis of Suspected Lung Tumor: A Case Report
}

\section{Alfredo Alonso Poza* \\ Profesor Colaborador, Hospital Universitario del Sureste de Madrid, Spain}

Received: July 11, 2017; Published: July 19, 2017

*Corresponding author: Alfredo Alonso Poza. FACS, Chairman, Jefe de Servicio de Cirugía General y Aparato Digestivo, Jefe de Estudios. Profesor Colaborador, Hospital Universitario del Sureste de Madrid. SERMAS, C/ Ronda del Sur, 10, 28500 Arganda del Rey (Madrid), Spain, Tel: 9183941 97; Email: alfredo.alonsop@salud.madrid.org

\section{Introduction}

Adrenal metastases at time of initial diagnosis occur in less than $10 \%$ patients with non small cell lung cáncer. To an adrenal mass and a pulmonary nodule, adrenal ectomy should be performed in suspected adrenal metástasis from a primary lung tumor.

\section{Case Report}

A 60-years old male, ex-smoker since seven month ago, COPD, and colonic polyps, presents fever of unknown origin. A computed tomography scan of the thorax and abdomen demonstrated a pulmonary node of $15 \mathrm{~mm}$ in the upper right lobe (Figure 1) and a left adrenal mass of $8 \times 9 \times 8 \mathrm{~cm}$ with out defined fat planes of the left kidney upper pole and the left renal vein pedicle (Figure 2). Bronchial biopsy was no posible with Flexible bronchoscopy. The core needle biopsy showed the tumoral in filtration. Were sected the left adrenal mass after ligation of the left adrenal vein by laparoscopic approach with four trocars and with out complications. The tumor was totally resected with the spleen and the left kidney because they seemed in filtrates; we left a drain at the upper left cuadrant. The operating time was 200 minutes. The resected specimen include a metastatic mass of $12 \times 10 \times 8 \mathrm{~cm}$, the spleen of $10 \times 6 \mathrm{~cm}$ and the left kidney of 9x6x4 cm (Figure $3 \& 4$ ). Microscopic examination confirmed metastatic adenocarcinoma originating from the lung. The spleen and the left kidney had not tumor in filtration. Post operatively the patient did well and was discharged on the third day.

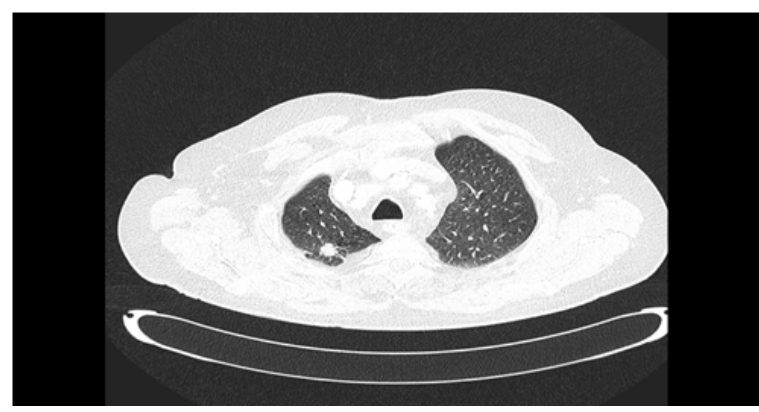

Figure 1: Upper right lobe.

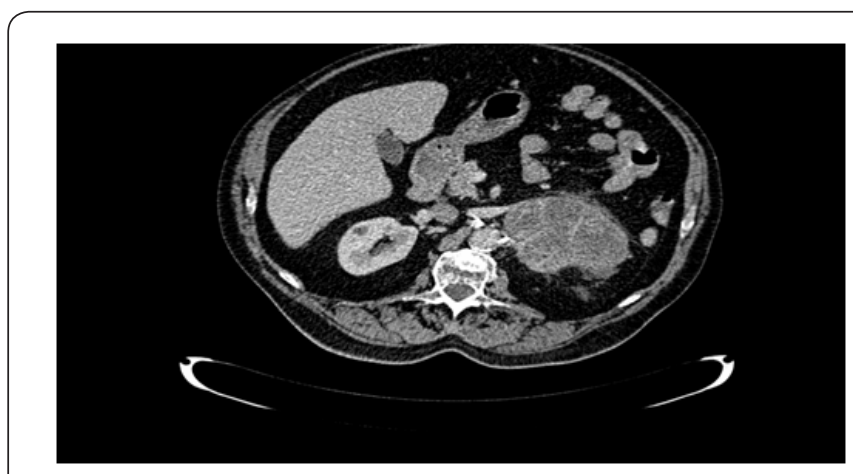

Figure 2: Left adrenal mass.

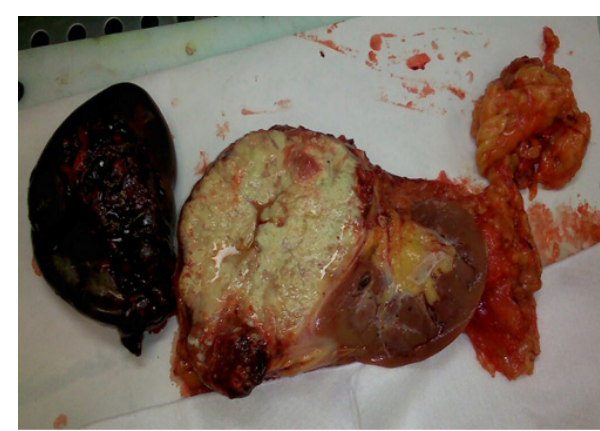

Figure 3: Spleen.

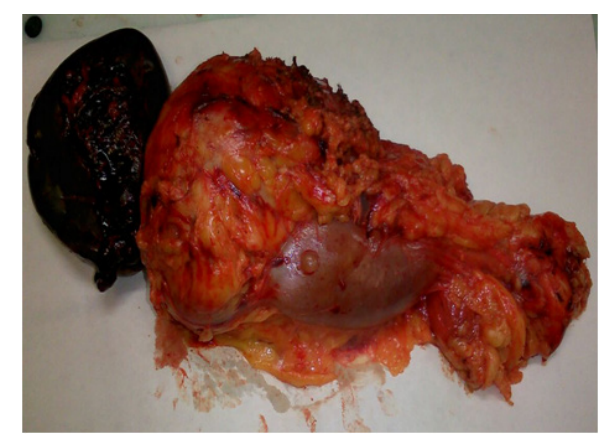

Figure 4: Left Kidney. 


\section{Conclusion}

Uncommonly the adrenal metastases may first appear as a single synchronous or metachronous metastasis. In patients with one single synchronous metastase with a un certain tumoral diagnosis, we believe that the metastase resection with a laparoscopic approach is use full together diagnosis and improve the survival.

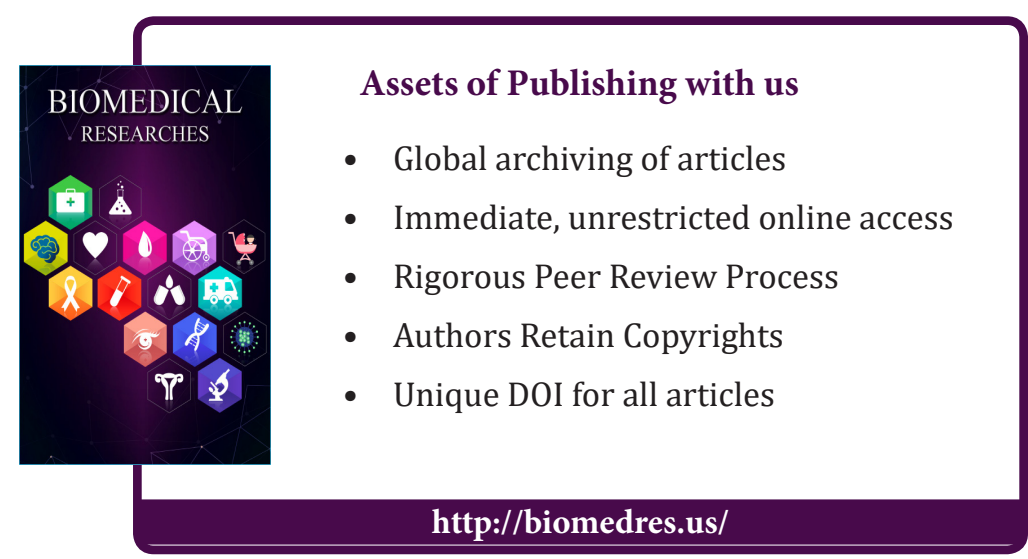

